\title{
Prurito y diabetes: pensar en un mal control de la glucemia y la posibilidad de fallo renal secundario
}

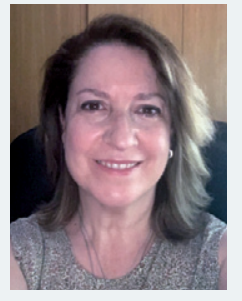

\section{Belén Morales Franco}

Médico adjunta. Servicio de Urgencias. Hospital de la Vega Lorenzo Guirao de Cieza.

Gerencia del Área IX del Servicio Murciano de Salud.

Murcia.

Mi paciente es una mujer de 75 años, jubilada, que acudió al servicio de urgencias por intenso prurito de piernas y brazos de un mes de evolución, que no mejoraba con tratamiento con ebastina de $20 \mathrm{mg}$, en dosis de 1 comprimido al día. Como antecedentes personales, presentaba diabetes de tipo 2 , hipertensión arterial y dislipidemia, en tratamiento diario con metformina de $850 \mathrm{mg}$, candesartán de $32 \mathrm{mg}$ y amlodipino de $10 \mathrm{mg}$. En el último control analítico hacía 6 meses, todos los parámetros se encontraban dentro de límites normales.

En la exploración física, destacaba una tensión arterial de 120/80 mm Hg, una glucemia en ayunas de $150 \mathrm{mg} / \mathrm{dL}$, un índice de masa corporal de $22,19 \mathrm{~kg} / \mathrm{m}^{2}$, máculas eritematosas en los antebrazos y las piernas, junto a lesiones erosivas por rascado (fig. 1). En la analítica, se objetivaron los siguientes valores: hemoglobina glucosilada $\left(\mathrm{HbA}_{1 \mathrm{c}}\right)$ del $7 \%$, urea de $230 \mathrm{mg} / \mathrm{dL}$, creatinina de $3 \mathrm{mg} / \mathrm{dL}$, y filtrado glomerular según la estimación de la ecuación MDRD (Modification of Diet in Renal Disease) de $13,81 \mathrm{~mL} / \mathrm{min}$.

Se sospechó que el prurito podía tener origen urémico por la insuficiencia renal. Se modificó el tratamiento, cambiando la metformina por metforminal sitagliptina y añadiendo insulina glargina en dosis de 12 UI y ácido acetilsalicílico en dosis de $100 \mathrm{mg}$.

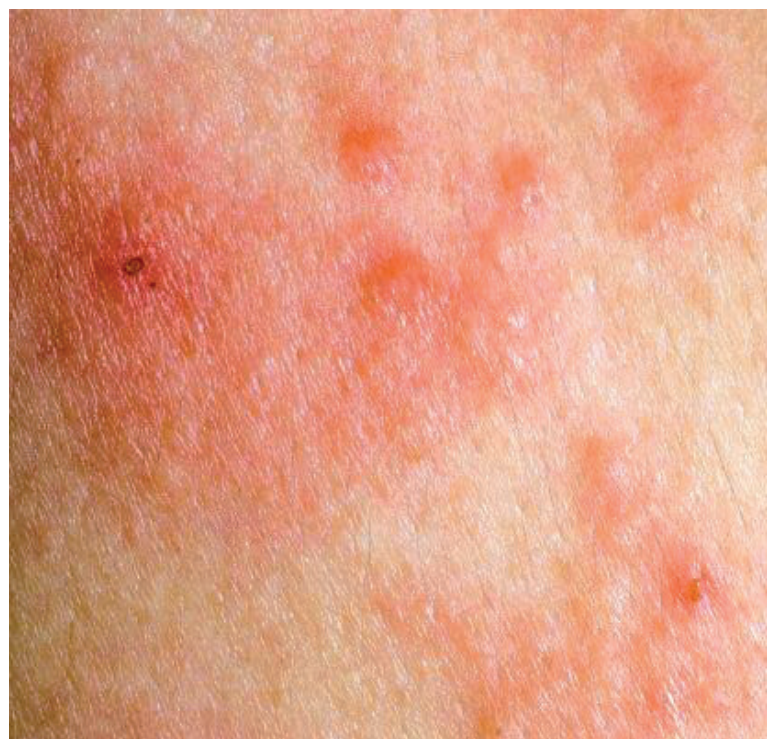

FIGURA 1. Imagen clínica de las lesiones de la piel de las piernas.

Revisada un mes después de esta modificación del tratamiento, la paciente mantuvo buenos controles glucémicos, mejoró la función renal y desapareció el prurito.

Presentar cifras elevadas de glucemia de manera mantenida puede aumentar el riesgo de padecer nefropatía, por lo que hay que optimizar su control 
Prurito y diabetes: pensar en un mal control de la glucemia y la posibilidad de fallo renal secundario Morales Franco B.

para evitarla ${ }^{1,2}$. En pacientes diabéticos con mal control glucémico y alteración de la función renal, la xerosis y el prurito son los síntomas dermatológicos que se presentan con más frecuencia ${ }^{3}$. Se ha relacionado un peor control de la $\mathrm{HbA}_{\mathrm{lc}}$ con el prurito en los pacientes con daño renal ${ }^{4}$.

El prurito es causa frecuente de consulta. Puede ser grave y condicionar trastornos del sueño, disminuyendo la calidad de vida. Es una sensación subjetiva desagradable y difícil de definir. Podemos decir que es la sensación que provoca la urgente necesidad de rascarse, estímulo que se origina de los terminales nerviosos de la dermis, las mucosas y la córnea, desde donde es transmitido por fibras finas y sin mielina (tipo C) hacia el asta dorsal de la médula espinal; cruzan la línea media y ascienden por los haces espinotalámicos laterales hasta el tálamo, siguiendo después el estímulo hacia el área sensorial de la circunvolución poscentral de la corteza sensorial, y generando una respuesta refleja espinal, que es el rascado 5 . Son intermediarios periféricos que estimulan las fibras $C$ e inducen el prurito la histamina, la tripsina, proteasas, péptidos (bradicinina, péptido intestinal vasoactivo y sustancia P) y sales biliares ${ }^{6}$.

El prurito es una manifestación clínica de numerosas enfermedades dermatológicas y sistémicas (tabla 1) $)^{2,7,8}$. Mi paciente presentaba patología

TABLA 1. Posibles etiologías del prurito

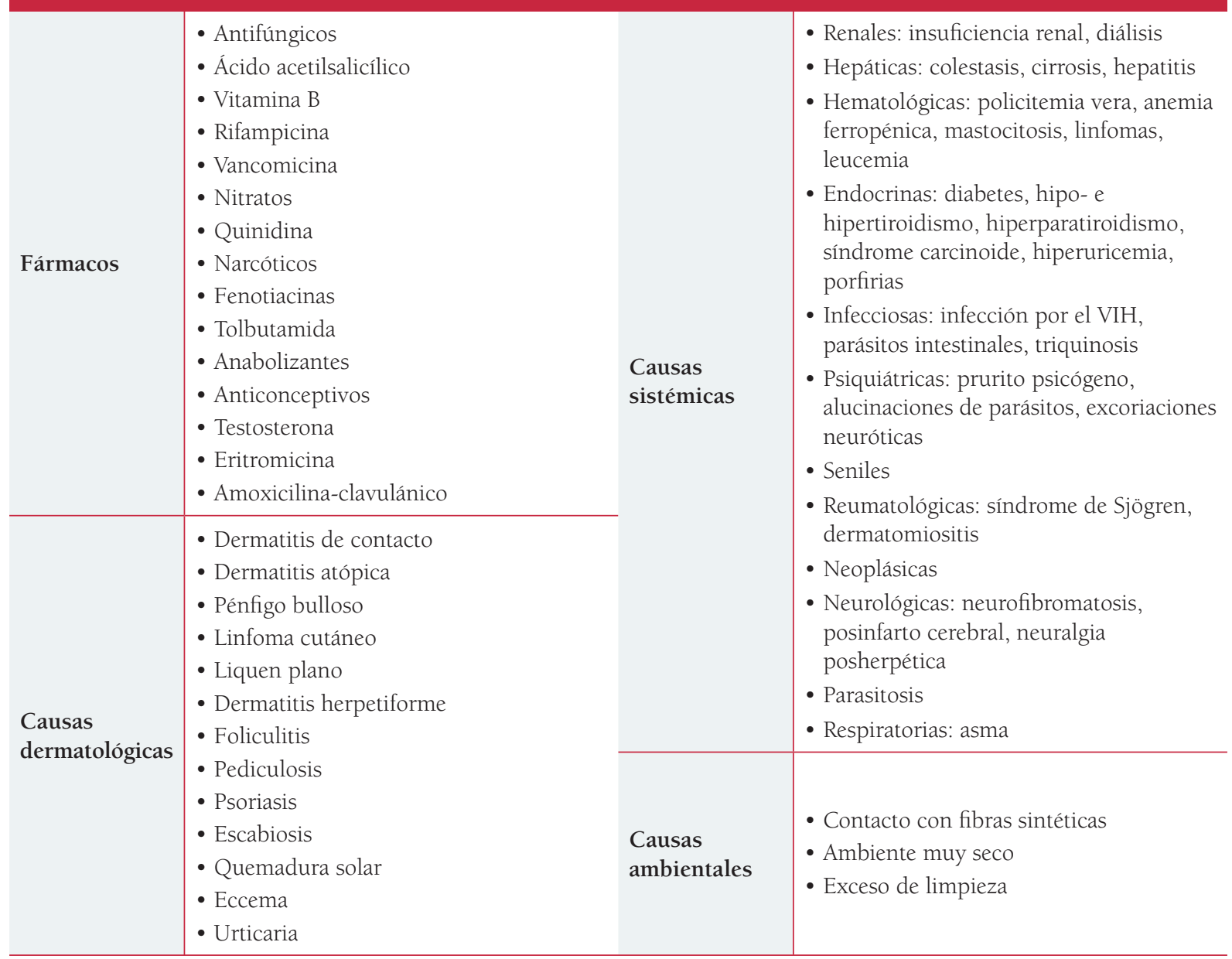

VIH: virus de la inmunodeficiencia humana. 
subyacente (mal control glucémico e insuficiencia renal), por lo que el tratamiento antihistamínico no fue efectivo, siendo necesario un control analítico para diagnosticar la etiología del prurito.

La nefropatía es una complicación frecuente en los pacientes diabéticos. El fallo renal puede ser el origen de la patología pruriginosa. Los estudios demuestran que los sujetos con fallo renal crónico tienen más manifestaciones cutáneas, como puede ser el prurito, que aquellos que no lo presentan ${ }^{3}$. En mi paciente, la insuficiencia renal se manifestó con prurito, demostrado por su desaparición al normalizarse la función renal. En este caso, el prurito nos sirvió de alerta de la posibilidad de alteración analítica.

Por todo ello, es importante en pacientes diabéticos mantener buenos controles glucémicos y evaluar la $\mathrm{HbA}_{\mathrm{lc}} \mathrm{y}$ la función renal cada 6 meses $^{1}$.

El prurito es un síntoma frecuente, que, sin duda, se presenta a diario en nuestras consultas de atención primaria y de urgencias, por lo que debemos estar entrenados mentalmente para orientar el problema, sea dermatológico o sistémico. Es fundamental recordar que, como en toda consulta dermatológica, lo primero que debemos llevar a cabo es la exploración física del paciente, inspeccionando la piel, sus anejos y las mucosas, valorando la presencia de lesiones cutáneas, sus características y localización. Debemos interrogar acerca del prurito: ritmo, horario, intensidad, tiempo de evolución, asociación a otros síntomas subjetivos cutáneos como el calor, la sensación de picaduras y el dolor, así como el lugar de residencia del paciente (área urbana, suburbana o rural), dieta, actividades laborales y deportivas, hábitos sexuales, y antecedentes personales y familiares ${ }^{9}$. Además, es importante tener en cuenta el tratamiento farmacológico del paciente. El dermatólogo a menudo es el primer consultor en este problema, y su valoración clínica debe incluir los datos analíticos, como en nuestra paciente ${ }^{10}$.

\section{BIBLIOGRAFÍA}

1. American Diabetes Association. Standards of medical care in diabetes - 2014. Diabetes Care. 2014;37 Suppl 1:S14-80.

2. Velilla-Zancada SM, Prieto-Díaz MA. Prurito en un paciente diabético, ¿indicador de lesión de órgano diana? Rev Cubana Med Gen Integr. 2014;30(4):498-501.

3. Falodun O, Ogunbiyi A, Salako B, George AK. Skin changes in patients with chronic renal failure. Saudi J Kidney Dis Transpl. 2011;22(2):268-72.

4. Afsar B, Elsurer Afsar R. HbAlc is related with uremic pruritus in diabetic nondiabetic hemodialysis patients. Ren Fail. 2012; 34(10):1264-9.

5. Savin JA. How should we define itching? J Am Acad Dermatol. 1998;39(2 Pt 1):268-9.

6. Larrondo RJ, González Angulo AR, Hernández García LM, Larrondo Lamadrid RP. El prurito. Síntoma frecuente en la atención primaria de salud. Rev Cubana Med Gen Integr. 2000;16(4): 392-6.

7. Reamy BV, Bunt CW, Fletcher S. A diagnostic approach to pruritus. Am Fam Physician. 2011;84(2):195-202.

8. Zirwas MJ, Seraly MP. Pruritus of unknown origin: a retrospective study. J Am Acad Dermatol. 2001;45(6):892-6.

9. Falabella R, Escobar C, Giraldo N. Dermatología. 5. a ed. Medellín: Carvajal; 1997. p. 195-201.

10. González-Guerra E. Prurito: aspectos psicológicos y calidad de vida. En: Guerra-Tapia A, Martínez Jordá R, Serra Baldrich E, Vilata Corell JJ (eds.). Actualización en urticaria. Prurito. Madrid: Editorial Luzán 5; 2012. p. 49-51. 